\title{
Antihypertensive drugs
}

Population Council

Follow this and additional works at: https://knowledgecommons.popcouncil.org/departments_sbsr-rh

Part of the Demography, Population, and Ecology Commons, Family, Life Course, and Society Commons, International Public Health Commons, Maternal and Child Health Commons, and the Medicine and Health Commons

How does access to this work benefit you? Let us know!

\section{Recommended Citation}

"Antihypertensive drugs," Ending Eclampsia brief. Washington, DC: Population Council, 2019.

This Brief is brought to you for free and open access by the Population Council. 


\section{BACKGROUND}

Hypertensive disorders of pregnancy (HDP) are major causes of severe morbidity, long-term disability, and death of mothers and babies. Globally, about 10 percent of women experience increased blood pressure (BP) during pregnancy, and 2-8 percent of pregnancies are complicated by pre-eclampsia. Among them, 10 percent develop severe pre-eclampsia and eclampsia. About 10-20 percent of all maternal deaths are from eclampsia, the second leading direct cause of maternal mortality.

Expanding proven, high impact practices is critical to accelerating a global reduction in maternal and perinatal morbidity and mortality. The need is especially acute in low- and middle-income countries (LMICs) of sub-Saharan Africa and South Asia, where 65-85 percent of the populations are rural and have limited access to life-saving care. Sixteen percent of all maternal deaths in LMICs are from HDP, with women in LMICs being 300 times more likely to die from eclampsia than those in developed countries.

The etiology of pre-eclampsia and eclampsia (PE/E) is unclear, but it is a multi-system disorder impacting cardiovascular and neurological functions. What is clear is PE/E-related deaths are preventable with early detection during antenatal care through BP monitoring and management with antihypertensive drugs and magnesium sulphate $\left(\mathrm{MgSO}_{4}\right)$.

$\mathrm{MgSO}_{4}$ is used for preventing and treating convulsions from severe pre-eclampsia and eclampsia, respectively, and is one of 13 essential commodities identified by the UN Commission on Life-saving Commodities for Women and Children. However, $\mathrm{MgSO}_{4}$ alone does not address the complex signs and symptoms that women with pre-eclampsia experience. Although safe, low-cost, and effective, $\mathrm{MgSO}_{4}$ is an anticonvulsant but it does not treat hypertension. If it is not stabilized, there is an increased risk of major adverse cardiovascular events, such as stroke and death. It is critical to use antihypertensive drugs to lower high BP.

\section{MANAGING HYPERTENSION DURING PREGNANCY}

Most women with pre-eclampsia have hypertension, meaning the systsolic BP is above $140 \mathrm{mmHg}$ and the diastolic BP is above $90 \mathrm{mmHg}$. Hypertension can be mild $(\geq 140 / 90-<150 / 100 \mathrm{mmHg})$, moderate ( $\geq 150 / 100-<160 / 110 \mathrm{mmHg}$ ), or severe $(\geq 160 / 110 \mathrm{mmHg})$. Moderate and severe hypertension require treatment with antihypertensive drugs.

\section{Highlights}

1. Pre-eclampsia is a condition in pregnant women marked by an increase in blood pressure and protein in urine after 20 weeks gestation.

2. Eclampsia is a life-threatening condition characterized by convulsions in women with PE.

3. $P E / E$ and other hypertensive disorders in pregnancy increase the risk of pre-term births.

4. Providing high quality and regular (ideally eight contacts) antenatal care improves the prevention and early detection of pre-eclampsia and can prevent its progression to eclampsia.

5. Prescribing low-dose aspirin and calcium to at-risk women can prevent pre-eclampsia and eclampsia.

6. Pre-eclampsia and eclampsia can be managed by administering antihypertensive drugs and magnesium sulphate $\left(\mathrm{MgSO}_{4}\right)$.

7. $\mathrm{MgSO}_{4}$ is the safest and most effective treatment for severe PE/E, and is one of 13 UN Life-Saving Commodities for Women and Children.

8. Improved prevention, increased detection, and effective treatment of PE/E can prevent unnecessarymaternal and newborn deaths.
The Population Council conducts research and delivers solutions that improve lives around the world. Big ideas supported by evidence: It's our model for global change. popcouncil.org

(c) 2017 The Population Council, Inc.
POPULATION COUNCIL

Ideas. Evidence. Impact. 
A Cochrane systematic review found that antihypertensive drugs low-er the risk of developing severe hypertension. The WHO recommends that every health facility have adequate oral and intravenous antihy-pertensive drugs in the antenatal, labor, and maternity units. If the sys-tolic blood pressure is $160 \mathrm{mmHg}$ or more or the diastolic blood pres-sure is $110 \mathrm{mmHg}$ or more, prescribe antihypertensive drugs. There are four antihypertensive drugs labetalol, hydralazine, methyldopa, and nifedipine - that are safe to use during pregnancy.

Despite being safe, low-cost, effective, and commonly available, LMICs, countries and programs do not procure antihypertensive drugs in quantities large enough to meet the demand for managing high BP in pregnancy. However in 2016, members of Maternal Health Caucus of the Repro-ductive Health Supplies Coalition agreed anti-hypertensives should be part of the essential medicines list for maternal health.

Challenges in ensuring that women have access to antihypertensive drugs to control their BP during pregnancy include the following:

- National task shifting policies do not allow management of HDP at the primary healthcare (PHC) facility level, even though they are mandated to administer a loading dose of $\mathrm{MgSO}_{4}$ prior to referral.

- Stock out of antihypertensive drugs at PHC facilities

- Additional cost of training PHC health workers to monitor BP and prescribe antihypertensive drugs correctly.

- Lack of support for task shifting from professional bodies.

The problem lies with national policies that enable or prohibit task shifting to providers at primary healthcare facilities. In many countries, the administration of a loading dose of $\mathrm{MgSO}_{4}$ to women with PE/E has been shifted to lower cadre providers (e.g., the community health extension workers), but the control of hypertension during pregnancy, including $\mathrm{PE} / \mathrm{E}$, is not included in national task shifting policies.

\section{CONCLUSION}

HDP, including PE/E, is a major cause of maternal and fetal mortality and morbidity globally. To prevent these deaths, early detection of the disease during pregnancy and appropriate use of antihypertensive drugs (and $\mathrm{MgSO}_{4}$, when indicated) are recommended for women with severe hypertension during and after pregnancy. It is, therefore, crucial that the four antihypertensive drugs that are safe to use in pregnancy - labetalol, hydralazine, methyldopa, and nifedipine - are included on the essential $\mathrm{MNH}$ drug list and distributed to every health facility in every country.

\section{REFERENCES}

1. World Health Organization. (2011). WHO Recommendations for Prevention and Treatment of Pre-eclampsia and Eclampsia.

2. von Dadelszen, P., et al. (2011). Pre-eclampsia in low and middle income countries. Best Practice \& Research Clinical Obstetrics \& Gynaecology, 25(4), 537-548. http://dx. doi.org/10.1016/S1701-2163(16)35405-6

3. Strobino, D., Werner, E., Mandal, M. (2015). Literature Review: Antihypertensive Medication in Pregnancy: An Update from the 2011 WHO Recommendations for Prevention and Treatment of Pre-eclampsia and Eclampsia.

4. UN Commission on Life-saving Commodities for Women and Children, Commissioners' Report 2012, Every Woman Every Child.

5. Su, Chen-Yi et al. (2013). Pregnancy Outcomes of Anti-Hypertensives for Women with Chronic Hypertension: A Population-Based Study. PLoS ONE, 8(2), e53844.

6. WHO Standards for Improving Quality of Maternal and Newborn Care in Health Facilities (2016)

7. WHO Integrated Management of Pregnancy and Childbirth: Managing Complications in Pregnancy and Childbirth: A guide for midwives and doctors (2017) Second Edition

8. PATH. (2014). Antihypertensive drugs for the management and treatment of hypertensive disorders or pregnancy.

9. Lalani, S. et al. (2013). Pharmacotherapy for Preeclampsia in Low and Middle Income Countries: An Analysis of Essential Medicines Lists. Journal of Obstetrics and Gynaecology Canada, 35 (3), 215-223.

10. www.endingeclampsia.org/resources 